\title{
JATI DIRI ORANG MELAYU MENERUSI NOVEL MALAISIE KARYA HENRI FAUCONNIER
}

\author{
THE SELF IDENTITY OF THE MALAYS BASED ON THE NOVEL \\ MALAISIE BY HENRI FAUCONNIER
}

\author{
Ani Omar \& Lajiman Janoory \\ Faculty of Languages and Communication, \\ Sultan Idris Education University, Tanjong Malim, Perak. \\ ani.omar@fbk.upsi.edu.my,lajiman@fbk.upsi.edu.my
}

\begin{abstract}
ABSTRAK
Sejak 84 tahun lalu, novel berteraskan rakaman sejarah mengenai citra kehidupan, budaya, adat resam, keindahan bahasa dan kesusasteraan Melayu daripada kaca mata lelaki Perancis, Henri Fauconnier sudah diterbitkan dalam bahasa Perancis. Novel Malaisie telah diterjemahkan ke pelbagai bahasa dunia termasuk bahasa Inggeris dengan tajuk The Soul of Malaya oleh penterjemahnya, Eric Sutton. Nurani Tanah Melayu tajuk novel Malaisie yang diterjemahkan ke dalam bahasa Melayu oleh Sasterawan Negara Prof. Emeritus Dr. Muhammad Haji Salleh, menanggapi dimensi baharu kehidupan yang dilalui dua pengurus estet, Lescale dan Rolain di Kuala Sampah, Selangor yang secara perlahan-lahan menyesuaikan diri, sekali gus mempelajari adat budaya pelbagai kaum di Tanah Melayu. Artikel ini selanjutnya menampilkan bagaimana Fauconnier mencerminkan realiti sepanjang beliau berkelana ke Tanah Melayu bermula tahun 1905 untuk memulakan penanaman getah. Pelbagai kisah menarik merangkumi kehidupan pelbagai kaum dimuatkan dalam novel ini. Lebih menarik, banyak pantun Melayu yang menghiasi setiap bab, malah Fauconnier turut menulis bahawa beliau terpikat dengan bait indah dan kiasan dalam khazanah puisi tradisional Melayu yang menunjukkan kesantunan masyarakatnya dalam berbahasa sekali gus menampilkan jati diri penuturnya. Keindahan sastera Melayu menerusi watak pembantu Lescale, iaitu Ngah dan Smail yang mengajaknya membaca buku dongeng lama seperti Cerita Kutu di Dalam Hutan dan Pak Belalang pula menunjukkan kebanggaan masyarakat dulu dalam memartabatkan bahasa dan kesusasteraan. Secara keseluruhannya Nurani Tanah Melayu adalah simbolik kepada kekuatan Melayu yang selama ini sering dipandang rendah oleh masyarakatnya sendiri, sedangkan ia dihormati oleh orang asing yang mengambil peluang mendalami keunikan budaya dan keseniannya. Dapatan kajian ini berupaya membuatkan nurani dan minda masyarakat supaya teguh kepada akarnya, tegar dalam menjaga kedaulatan bangsa dan lebih patriotik seperti saratnya cinta Fauconnier kepada Tanah Melayu.
\end{abstract}

Kata Kunci: Jati diri, budaya, kekuatan, Melayu

\begin{abstract}
Eighty-four years ago a novel based on history relating to the lives, cultures, customs, language and literary aesthetics of the Malays from the perspective of Henri Fauconnier, a Frenchman, was published in French. The novel, Malaisie, has also been translated into various languages including in English with the title The Soul of Malaya by Eric Sutton. Nurani Tanah Melayu, the Malay translation by the National laureate, Emeritus Professor Dr. Muhammad Haji Salleh, recounts the experiences of two estate managers, Lescale and Rolain in Kuala Sampah, Selangor who gradually adapt themselves to and learn the customs and cultures of the various ethnics in the Malay Archipelago. This article exposes Fauconnier's experience as a sojourner in the Malay Archipelago from 1905 as a planter in the rubber industry. The novel reverberates with the diverse lives of the multi-cultural society. More interestingly, the novel includes many Malay pantuns that intersperses each chapter. Furthermore, Fauconnier also reveals how he is fascinated by the beauty and metaphorical language of the pantuns that reflect the courteous and civil nature of the Malay language. These qualities in language, in turn, suggest the inner identity of the utterers. The beauty of Malay literature as reflected in the novel through
\end{abstract}


Ngah and Smail, Lescale's helpers, who invite him to read old myths such as Cerita Kutu di Dalam Hutan and Pak Belalang, show how the older Malay generations were proud of their language and literature. In essence, Nurani Tanah Melayu is symbolical of the self identity of the Malays which are always denigrated by its own people but respected by outsiders who take the opportunity to deepen their knowledge of the Malay culture and arts. The research finding allows the Malays to appreciate their own culture and sovereignty and to be more patriotic similar to Fauconnier's love of the Malay Archipelago.

Keywords: Self identity, culture, strength, Malays

\section{PENGENALAN}

Nurani Tanah Melayu tajuk novel Malaisie karya Henri Fauconnier yang telah diterjemahkan ke Bahasa Melayu oleh Muhammad Haji Salleh (2015) menceritakan kehidupan dua orang pengurus estet, Lescale dan Rolain, di Kuala Sampah, Selangor. Di sana, mereka belajar memahami dan menyesuaikan diri dengan pekerja Tamil, Cina dan penduduk Melayu. Wajah Tanah Melayu dipersembahkan mengikut gaya kefahaman Fauconnier menyerlahkan kecintaannya terhadap sisi budaya masyarakat tempatan yang dihuraikan dalam empat bab utama iaitu "Penanaman Getah", "Pondok Nibung", "Kembara" dan "Amuk". Dalam proses memahami, mereka menyelami ritual, adat dan budaya setiap kaum. Walaupun Fauconnier tidak menampilkan dirinya sebagai watak utama, kebanyakan kisah yang diadun dalam gaya fiksyen itu mencerminkan realiti sepanjang beliau berkelana ke Tanah Melayu bermula tahun 1905 untuk memulakan penanaman getah. Kebanyakan kisah menarik perhatian antaranya bagaimana Lescale dan Rolain bekerja dengan masyarakat tempatan di ladang getah yang majoritinya terdiri daripada bangsa India, sekali gus turut menampilkan kisah perbezaan kasta. Lebih menarik lagi banyak pantun Melayu yang menghiasi setiap bab, malah Fauconnier turut menulis bahawa beliau terpikat dengan bait indah dan kiasan dalam khazanah puisi tradisional Melayu yang menunjukkan kesantunan masyarakatnya dalam berbahasa.

Keindahan sastera Melayu menerusi watak pembantu Lescale, iaitu Ngah dan Smail yang mengajaknya membaca buku dongeng lama seperti Cerita "Kutu di Dalam Hutan" dan "Pak Belalang" pula menunjukkan kebanggaan masyarakat dulu dalam memartabatkan bahasa dan kesusasteraan. Kedua beradik ini juga turut memperkenalkan sudut pandang dunia, kepercayaan, istiadat serta gaya berhibur dan bercinta cara Melayu. Jarang terdapat usaha yang agak penuh begini untuk memahami budaya dan manusia yang sangat berlainan budaya daripada budaya penulisnya. Hasilnya bermutu tinggi, canggih dan berani.

Karya ini memenangi Prix Goncourt, sebuah anugerah sastera Perancis tersohor tahun 1931. Buku itu adalah inisiatif ITBM dalam memulihara dan memperbanyakkan khazanah perpustakaan dan kesusasteraan negara khususnya buku mengenai Malaysia dari luar negara. Sidang Barbezieux buat julung kalinya menghimpunkan semua pengkaji dan komuniti pantun di Perancis diadakan khusus selepas 85 tahun penerbitan 'Malaisie' tulisan Henri Fauconnier. Karya Fauconnier ini menjadi pencetus kepada perkembangan pantun di Perancis kerana diselitkan beberapa kerat pantun bahasa Melayu walaupun seluruh teks yang lain ditulis dalam bahasa Perancis.

Bagi orang Malaysia, ada beberapa perkara yang dapat dipelajari daripada pengarang bijaksana ini; antaranya ialah falsafah tradisional dan pandangan hidup orang Melayu. Penilaian Fauconnier terhadap pantun pula cukup tajam serta benar, dan dapat dihayati hingga hari ini. Beliau meneroka semua ini "untuk mendapatkan wawasan ke dalam nurani Malaya". Novel ini telah diterjemahkan ke dalam banyak bahasa, Muhammad Haji Salleh, seorang penterjemah yang berpengalaman, akhirnya berjaya membawa kebijaksanaan dan kehalusan bahasa asalnya ke dalam bahasa Melayu yang sama halus dan canggih. 


\section{OBJEKTIF KAJIAN}

i. Mengenalpasti falsafah tradisional dan pandangan hidup orang Melayu dari kaca mata orang Perancis yang datang ke Tanah Melayu tahun 1905.

ii. Memahami penilaian Henri Fauconnier terhadap pantun orang Melayu yang dikatakan melambangkan jati diri, cukup tajam serta benar.

\section{METODOLOGI}

Kajian ini berbentuk kualitatif iaitu mengkaji teks dengan menelaah novel Nurani Tanah Melayu (Malaisie) karya Henri Fauconnier yang telah diterjemahkan oleh Sasterawan Negara Muhammad Haji Saleh dan telah diterbitkan oleh Institut Terjemahan Negara tahun 2015. Kajian kepustakaan juga dijalankan dengan meneliti pengkajian yang berkaitan dengannya dan telah diterbitkan sama ada dalam bentuk jurnal, prosiding dan sumber-sumber yang lain.

\section{DAPATAN}

Bahagian ini akan tertumpu kepada beberapa contoh yang mengambarkan falsafah tradisional dan pandangan hidup orang Melayu dari kaca mata Henri Fauconnier yang datang ke Tanah Melayu tahun 1905. Di selitkan juga beberapa contoh pantun, mantera, mengikut penilaian Fauconnier yang mengatakan pantun orang Melayu cukup tajam serta benar.

Sehubungan itu, tidak keterlaluan jika dikatakan bahawa masyarakat Melayu yang digambarkan dalam novel ini berada pada tahap primitif, segala aktiviti kehidupan dijalankan secara lisan sepenuhnya apabila setiap ahli masyarakat berhubungan antara satu sama lain melalui komunikasi lisan. Sesuai dengan tingkat pemikiran yang sederhana ini, mereka menyesuaikan kehidupan dengan persekitaran alam sekeliling dalam meneruskan kelangsungan hidup. Pada tahap ini lahirlah dalam kalangan masyarakat itu suatu fenomena ujaran kata-kata indah yang bersifat sederhana dan dapat dijadikan panduan dalam kehidupan sama ada dalam bentuk prosa mahupun puisi yang diistilahkan sebagai sastera lisan. Fenomena inilah yang dialami oleh masyarakat Melayu ketika itu. Mohd Taib Osman (1982) membahagikan tradisi lisan kepada tiga komponen asas iaitu tradisi yang berbentuk perlakuan (behavioural). Tradisi berbentuk perlakuan ini ialah tradisi yang dilakukan atau diamalkan oleh pemiliknya seperti adat resam, perbomohan, perayaan (ceremonies), teater tradisional, permainan rakyat, tarian dan segala bentuk pertukangan serta kemahiran dalam aktiviti harian mereka. Keduanya tradisi budaya benda (material culture) yang merujuk kepada artifak-artifak warisan yang dihasilkan daripada aktiviti tradisi perlakuan seperti busana, alat muzik, seni bina, alatan hiasan diri, alat persenjataan, anyaman, tembikar, pertukangan perak dan tenunan. Seterusnya, komponen yang ketiga tradisi lisan ialah tradisi yang berbentuk pengujaran (verbalized). Tradisi lisan jenis ini meliputi segala bentuk tradisi yang diujarkan melalui perantaraan mulut dan dikenali juga sebagai sastera lisan atau sastera rakyat. Di dalam novel ini ada digambarkan ketiga-tiga bentuk tradisi lisan tersebut yang menjadi asas kepada bentuk perlakuan pemiliknya seperti aspek perbomohan untuk memulihkan penyakit, aspek hiburan seperti nyanyian dan tarian dengan busananya yang menawan serta yang berbentuk pengujaran iaitu pantun yang menjadi medium utama dalam berkomunikasi masyarakat Melayu pada awal abad ke-20 yang menggambarkan ketinggian keintelektualan orang Melayu dengan berpandukan keindahan dan kekayaan alam ciptaan Tuhan. Walaupun dalam masa yang sama mereka dikatakan daif dan primitif, tetapi bait-bait pantun orang Melayu cukup tajam dan benar, seperti yang diakui oleh Fauconnier. Perkara ini dapat dibuktikan dalam kisah kehidupan, falsafah dan bait-bait mantera, pantun, nyanyian yang diselit dalam novel kisah benar ini oleh Henri Fauconnier. Untuk huraian selanjutnya akan diperturunkan beberapa contoh bait-bait pantun yang terdapat dalam novel ini, umpamanya permulaan bab satu (Penanam Getah) 
terdapat serangkap pantun yang mengambarkan kegembiraan dan keterujaan Fouconnier buat permulaannya menjadi pengurus di sebuah ladang getah di Kuala Sampah, Selangor pada ketika itu. Seperti pantun berikut;

\author{
Jikalau tidak kerana bintang, \\ Masakan bulan terbit tinggi; \\ Jikalau tidak kerana abang, \\ Masakan datang adik ke mari
}

(hlmn. 3)

Gambaran masyarakat berbilang kaum yang hidup dengan harmoni juga digambarkan dalam kenyataannya seperti berikut;

\begin{abstract}
"beberapa orang yang rencam warna pakaiannya mengerumuni mereka; Melayu berkulit sawo matang, Tamil berkulit hitam, Cina, pula dengan wajah kekuningan limau di bawah terik Matahari khatulistiwa. Mereka kelihatan sedang matang seperti sebiji oren panas. (hlmn. 3)
\end{abstract}

Seperti yang diperkatakannya lagi;

"Di Bukit Sampah, saya menemukan Tanah Melayu yang baharu dan lebih terbuka hatinya. Saya telah melepasi tahap kegelisahan pada awalnya, serta mula merasai kegembiraan yang tenang, dan sepatutnya menemani perasaan kasih sayang dengan mata terbuka. (hlmn. 27)

Dalam bab dua pula (Pokok Nibung) dimulai dengan pantun dua kerat, yang menggambarkan perbezaan kehidupan antara di Tanah Melayu dengan di Eropah. Namun semuanya dapat ditangani dengan bijaksana seperti maksud yang tersirat dalam pantun yang dipaparkan;

Padang perahu di lautan,

Padang hati di fikiran.

(hlmn. 45)

Seterusnya Fauconnier menurunkan falsafah tradisional dan pandangan hidup orang Melayu dari kaca matanya seperti berikut;

"sudut pandangan kita bertentangan dengan sudut pandangan mereka. Mereka biasa mendapat keperluan beras dengan hanya bekerja selama seminggu dan mereka tidak menuntut lebih daripada itu. Semua keletihan dianggap sesuatu yang sia-sia sahaja dan juga berbahaya. Perjalanan hidup itu panjang - mengapakah perlu tergesa-gesa? Pada waktu pagi, mungkin mereka pergi melihat pukat di sepanjang sungai atau jerat di pinggir hutan, dan di sana mereka akan bertemu dengan makhluk hutan dan air, yang diizinkan Allah SWT untuk menangkapnya, supaya jasad mereka dapat menjadi jasad manusia, manakala roh mereka dapat memasuki roh manusia, mungkin mengenali-Nya dengan lebih baik. Jika Dia mengizinkan, sebabnya ialah Dia telah menjadikan sesikat pisang masak di suatu sudut kampung, ataupun rebung, iaitu sayur yang sedap dimakan tersedia untuk dipotong. Mereka percaya, tidak lama kemudian akan ada buah-buahan untuk dimakan bersama dengan nasi. Keesokan harinya, mungkin takdir akan lebih bermurah hati, dan akan ada lebih banyak lagi." (hlmn. 47)

Petikan di atas menggambarkan betapa orang Melayu dahulu kala digambarkan dengan perumpaaman "kais pagi makan pagi kais petang makan petang".

Seterusnya dalam bab yang sama Fauconnier menggambarkan betapa orang Melayu mempercayai sesuatu benda yang hidup itu mempunyai semangatnya. Perhatikan perbualan antara Fauconnier dengan pembantunya Smail seperti berikut; 
"Smail, kamu tahu mengapa cicak berhenti sejenak sebelum melompat menangkap lalat?

"untuk memberinya waktu berdoa kepada Allah," dia menjawab tanpa ragu-ragu.

"Haiwan juga berdoa kepada Allah?"

Dia kelihatan terkejut mendengar kejahilan saya

"Mengapa pula tidak?"

"Beras yang kamu hendak tanak itu juga berdoa?"

"Tuan mentertawakan saya."

"Tidak, Smail, saya ingin tahu kepercayaan orang Melayu. Tidakkah Tuan Rolain bertanyakan soalan begini?"

"Orang putih," kata Smail, "Bertanyakan soalan yang ditanya oleh anak-anak." Dia menambah, "Kita makan nasi, tapi kita tidak makan semangatnya."

Bagi saya, ini tidak ada ertinya sama sekali. Saya patut bertanya sama ada roh lalat dimakan. Akan tetapi, perkataan yang saya gunakan untuk "roh" itu terasa canggung sedikit. Roh haiwan, roh tumbuhan, malah roh emas atau besi - bagaimanakah kita akan memahami konsepnya? Walaupun logic saya sudah tersasar, saya tidak berani menganggap bahawa Smail itu seorang yang bodoh. Apa yang dikatakannya mungkin menyimpan sebutir kebenaran, dan seharusnya mempunyai makna. Logik naluriah berkata demikian kepada saya. (hlmn. 48)

Pernyataan Fauconnier diperkukuhkan lagi seperti maksud pantun dua kerat dan empat kerat seperti berikut;

Murai gila jadi tekukur

Ajaib hairan hati tafakur

(hlmn.58)

Kepercayaan orang Melayu kepada semangat dan roh diperkuatkan lagi dengan petikan berikut;

"Ada terlalu banyak semangat dan roh di dalam hutan," kata Smail perlahan, "Lebih banyak semangat dan roh daripada nyamuk. Ada sesetengah semangat dan roh pada setiap pokok. Kalaulah dengan tuan yang lain saya takkan berani hidup di sini."

"Maafkan saya tuan, kalau saya minta tuan katakan kepada Tuan Rolain supaya jangan selalu ke hutan dan duduk di sana sampai lewat senja. Lihat, langit sedang menguning..." (hlmn 59)

Walaupun sudah memeluk agama Islam, Fauconnier mempercayai bahawa orang Melayu ketika itu masih berpegang kepada tiga lapis kepercayaan iaitu animism, hinduisme dan Islam. Ini seperti kenyataannya seperti berikut:

Sebagai penganut Islam orang Melayu sangat teguh, tetapi bukan sebagai pengikut yang ortodoks. Doa mereka yang bermula dan berakhir dengan nama Allah, sebenarnya ditujukan kepada ribuan hantu yang ditolak oleh Nabi mereka. Allah Maha Penyayang - dan mereka tidak lupa mengingati-Nya setiap hari. (hlmn. 61)

Rumusannya Fauconnier menyatakan bahawa orang Melayu pada waktu itu mempercayai kepada semangat dan roh yang boleh mempengaruhi kehidupan mereka. Perbualan antara Smail dengan tuannya Fauconnier dan Roland tidak pernah jemu didengar dan diikuti kerana ia diselang selikan dengan bait-bait pantun seperti yang diungkapkan. Perhatikan pantun berikut seperti mana yang difahami oleh Fauconnier mengenainya.

Asam kandis asam gelugur,

Ketiga dengan asam rembunia;

Nyawa menangis di pintu kubur,

Hendak pulang ke dalam dunia.

(hlmn. 63) 
Nyawa menangis di pintu kubur,

Hendak pulang ke dalam dunia.

(hlmn. 63)

Nasi basi di atas para,

Nasi masak dalam perahu;

Pucat kasih badan sengsara,

Hidup segan mati tak mahu.

(hlmn. 63)

Pantun yang pendek begini harus dibaca perlahan-lahan, seperti suatu lukisan benda tidak bernyawa, yang harus ditatap lama-lama. Demikian mengikut Fauconnier.

Kerengga di dalam buluh,

Serahi berisi air mawar;

Sampai hasrat di dalam tubuh,

Tuan seorang jadi penawar.

(hlmn. 64)

Akar keramat akar bertuah,

Akar bertampak di gua batu;

Nabi Muhammad kekasih Allah,

Di manalah tuan masa itu?

(hlmn. 64)

Rumusannya mengikut Fauconnier puisi tidak mungkin diterjemahkan, tetapi dalam masalah terjemahan pantun, yang menjadi persoalan bukan sahaja rentak, rima dan asonansinya yang tercicir. Permainan bahasa, frasa yang bolak-balik dan alusi haruslah yang mempesonakan orang Melayu. Selanjutnya Fauconnier menyatakan;

"kita harus lama tinggal bersama dengan orang Melayu untuk menangkap konotasi setiap kata, selain makna harfiahnya. Mereka menghafal rangkapnya dan selalu menggubah yang baharu. Percakapan mereka sarat dengan unsur puitis, tetapi mujarad. Ada satu permainan lompat katak antara yang konkrit dengan yang mujarad, apabila orang yang mengambil bahagian selalu berubah-ubah tempatnya. Kebimbangan kita adalah supaya dapat mengalihkannya secara jelas, iaitu dengan mencerakinkan naluri gagasannya... (hlmn. 64)

Selanjutnya beliau menyatakan seperti berikut;

"pantun pertama yang saya baca menghiburkan saya laksana sebuah lukisan "teka-teki" yang harus dikembalikan kepada seluruh nuansa dan ertinya untuk mencari raut garis yang terselindung di bawah objek yang tersurat." (hlmn. 65).

Mengikut Fauconnier falsafah hidup orang Melayu juga banyak dipengaruhi oleh percaya adanya hantu. Ini seperti yang didengarinya dari Smail dari cerita-cerita hantu yang disampaikannya.

"malam itu saya diperkenalkan kepada banyak jenis hantu. Hantu Mati Anak, yang mati di dalam perut ibunya, Langsuir, mati semasa melahirkan, hantu Golek, yang keluar dari kubur dan melompat serta bergulung di atas tanah, yang dibalut dengan kain kapan... (hlmn. 68)

Mengikut Fauconnier lagi; yang ditakuti orang Melayu ialah fikiran orang mati, semangat mereka, perbuatan mereka, yang akhirnya dibebaskan dan hidup secara berleluasa - segala-galanya yang diwariskan oleh takdir kepada suratan nasib.

Puisi telah lama terlahir dalam sejarah peradaban manusia. Sebagaimana yang disebut oleh Dharmawijaya (1998:12), beliau mengatakan bahawa puisi telah diterima umum sebagai bentuk karya sastera yang paling tua. Karya-karya agung seperti Mahabrata, Ramayana, Oedipus, Hamlet dan 
Macbeth ditulis dalam bentuk puisi. Malah puisi membuka nuansa jauh yang lebih luas seperti yang dikatakan oleh Muhammad Haji Salleh (2009:9) bahawa puisi banyak menyimpan genius bangsa, cara, adat istiadat, kecenderungan, sudut pandangan dan konsepsi alam. Sesungguhnya puisi mempunyai kedudukan istimewa dalam tamadun dunia malah mempunyai kedudukan yang amat rapat dengan orang Melayu. Puisi bukan sekadar warisan kebudayaan yang menggambarkan orang Melayu malah puisi merupakan khazanah orang Melayu yang memberikan citra kepada orang Melayu semenjak dahulu lagi. Di dalam bab selanjutnya iaitu bab tiga (Kembara) puisi Melayu seperti pantun terus dirakamkan oleh Fauconnier seperti rangkap berikut;

Kupu-kupu terbang melintang,

Terbang di laut di ujung karang;

Pasal apa berhati bimbang,

Dari dahulu sampai sekarang?

Tujuh gunung sembilan lautan,

Kalau tak mati saya turutkan

(hlmn. 74)

(hlmn. 87)

Sebuah lagu Melayu diselitkan juga;

Pergilah anak-anak pergi mandi,

Sejukkan tubuh yang panas seperti kuih,

Bersihkanlah tubuh yang ditepung abuk,

Sembunyikan tubuhmu dalam air payau,

Telanjang bulat seperti kerbau yang kehilangan gelang

Di hidungnya,

Telanjang seperti cicak dengan simpul di atas kepalanya,

Jambulmu sudah lekat pada kepalamu - jaga-jaga,

Jangan tenggelam,

Malaikat Jibrail tidak tahu bagaimana hendak membawamu.

(hlmn. 97)

Sketsa juga diselitkan;

Tuan saya paling baik, hatinya hadir di hadapan saya

Matanya melihat apa yang ada di luar kepala saya

Tuan saya paling baik, bijaksananya hadir di depan hati saya

Hatinya melihat apa yang ada di sebalik mata saya

(hlmn. 98)

Seperti yang telah dimaklumkan, pantun adalah puisi Melayu asli ,dicipta dalam masyarakat Melayu; iaitu bukan daripada puisi Jawa, India atau Cina. Bagi masyarakat Melayu pantun merupakan ciri penting dalam kesenian mereka. Dalam kehidupan orang Melayu pantun bukan sahaja digunakan dalam nyanyian, bahkan dipakai dalam percakapan atau ucapan, dalam perbualan, adat istiadat dan sebagainya. Betapa pun perubahan berlaku dalam bahasa dan kesusasteraan Melayu, namun pantun mempunyai tempatnya yang khusus dan istimewa. Perubahan boleh terus berlaku dalam berbagai-bagai aspek budaya Melayu, namun pantun tetap wujud dalam bentuk aslinya. Ia tidak dapat ditokok tambah atau dikurangkan bentuk dan sifatnya tetapi dapat disesuaikan dengan perkembangan bahasa dan kemajuan kehidupan masyarakat Melayu.

Pantun selalu dianggap sebagai alat komunikasi antara anggota-anggota masyarakat. Pantunpantun yang bertemakan kasih sayang adalah hasil komunikasi daripada kegiatan menggunakan pantun dalam suasana berkasih sayang, sama ada diucapkan secara langsung, melalui lambang atau tulisan, atau melalui perantaraan suatu suasana yang berkenaan. 
Laksana buah kepayang,

Dimakan mabuk dibuang sayang.

(hlmn. 117)

Terdengar air di jantung kelapa,

Durian kuning menyimpan rahsia;

Aku tahu kurinduimu sentiasa,

Mengapakah kau rindukan bibirku pula?

(hlmn. 129)

Di mata gadis jejaka sebiji durian,

Kasar dan berduri - bakal melukakan;

Setelah jijik dan takut, tibalah keinginan,

Selepas itu berahi tumbuh berkepanjangan.

(hlmn. 129)

Kupaslah buah baunya sekali,

Tak seorang merasa jemu;

Bijinya seakan telur, melepasi jari,

Isinya bagai bawang dan susu

Mumbang kelapa tidak berair,

(hlmn. 129)

Bulan di atas meneguknya;

Nyiur semantan pun bukan,

Nyiur sudah dimakan bulan.

(hlmn. 130)

Puisi Melayu tradisional seperti pantun, syair, gurindam, seloka dan nazam adalah pancaran nilai dan pemikiran masyarakat Melayu tradisional. Bentuk dan isi pemikirannya bukan sahaja berguna dalam konteks zamannya malah relevan untuk setiap masa dan latar masyarakat Melayu dan keseluruhan masyarakat yang berbilang kaum di Malaysia hari ini.

Dalam bab empat (Amuk) dibentangkan pula tentang kepercayaan kuasa ghaib bagi orang Melayu. Berikut digambarkan seperti pernyataan Fauconnier;

"kuasa ghaib ini tidak dapat mengharungi perbendaharaan kita. Yang diperlukan hanyalah untuk mentafsirkan fikiran yang melayang-layang di udara di sekeliling kita. Itulah yang dilakukan oleh orang Melayu. Kuasa ghaib di Tanah Melayu itu bisu; tetapi mereka memahaminya.” (hlmn. 52)

Terang bulan terang temaram,

Hantu berjalan laki bini.

(hlmn. 133)

Mambang kuning mambang kelabu

Pantat kuning disemburkan abu!

(hlmn.148)

Selain dapat meluahkan perasaan, puisi Melayu lama merupakan alat komunikasi yang berkesan. Ia lebih kerap dan menjadi satu kemestian dalam aspek ritual atau upacara-upacara. Menurut Harun Mat Piah (1989:4), aspek ritual atau upacara dapat dilihat hampir dalam kesemua fungsi dan peranan yang diambil oleh puisi ini, yang seluruhnya dapat digunakan dalam pelbagai kegiatan yang bersifat ritual, baik yang berupa magis, mahupun yang berunsur agama atau hiburan. Dalam bab ini mantera juga diselitkan seperti berikut;

Aku tahu namamu dan asalmu

Kau kotor tapi dibersihkan

Terjadi daripada air mata Muhammad 
Apabila baginda berhijrah dari Makkah

Dalam abu padang pasir

Dipandu oleh seorang kafir

Menutup mata butanya disebabkan tangismu...

(hlmn. 151)

Masuklah ke taman nikmat

Semerbak dengan bau-bauan dan burung-burung

Diciptakan Allah

Dipersembahkan oleh adik saya Smail

Terimalah taman nikmat ini

Tunjukkanlah kepada saya penyakit adik saya ini.

(hlmn. 151)

O Badi ! O Badi ! O Badi!

Masuklah dalam jambak daun

Seraplah inti daun-daun itu

Ketujuh-tujuh keracunan daripada daun-daun itu

Kembalilah ke tempat asalmu

Dalam air yang mengalir dan meresap

Dalam tiupan angin yang sudah berhenti

Dalam kurang mereh dari bumi

Kepada tanah rata tanpa rumput

Kepada laut tanpa pantai

Kepada ruang yang tidak terbentang

Demi kekuatan La-ilaha-illa-illah...

(hlmn. 154)

Hendak pucuk pucuklah jering, Jering tak biasa pucuk di dahan;

Hendak kokok kokoklah biring,

Biring tak biasa kalah di medan.

(hlmn. 165)

Kalau tuan mudik ke hulu,

Carikan saya bunga kemboja;

Kalau tuan mati dahulu,

Nantikan saya di pintu syurga.

(hlmn. 175)

Puisi sebagai karya kesusasteraan tidaklah sekadar untuk dibaca dan didengar. Puisi yang unsur-unsurnya kaya dengan nilai-nilai kerohanian itu perlu difahami atau dihayati. Bagi mencapai matlamat memahami ini, seseorang pembaca atau peneliti hendaklah terlebih dahulu membebaskan diri dari konsep bahawa puisi itu susah atau rumit. Cuma yang perlu ketika menghadapi puisi ialah membina sikap kesungguhan, perasaan yang peka, imaginasi yang kuat dan fikiran yang terbuka.

Setiap jenis puisi lama terungkap melalui kemahiran penciptanya memilih dan menyusun kata-kata daripada suasana alam dan persekitarannya serta menjalinkannya dengan bunyi. Dalam pemilihan, penyusunan dan perjalinan itu tergambar pernyataan perasaan, pemikiran dan aktivitiaktiviti masyarakat yang kebanyakannya secara halus. Melalui gambaran-gambaran seperti itulah dapat dikesani 'nilai-nilai murni' seperti kerjasama, kesetiaan, kejujuran, ketabahan dan seumpamanya sebagai ikhtibar kehidupan manusia.

Demikianlah beberapa contoh yang sesuai membincangkan kedudukan puisi Melayu yang telah dirakamkan oleh Henri Fauconnier, sebagai cipta sastera yang unik untuk dijadikan pedoman dalam mengangkat paradigma generasi masa kini. Keunikannya akan terus diwarisi oleh generasi yang akan datang dan tidak mungkin akan terhapus di telan zaman, seperti yang tergambar dalam 
ungkapan 'tidak akan Melayu hilang di dunia'. Namun kebimbangan tetap terasa kerana ciptaan puisi yang terus dipinggirkan di tengah ledakan siber internet masa kini. Langkah-langkah yang lebih wajar perlu diambil khasnya dikalangan para ilmuan dan pengkarya di bidang ini untuk terus berpuisi dan menunjukkan ciri-ciri kecemerlangan dan sepatutnya ada bersama di laman internet supaya dikenali dan diminati oleh generasi masa kini dan akan datang, bukan sahaja dirantau ini malah di seluruh dunia.

Setelah mengkaji novel ini apa yang boleh diperkatakan dari segi intrinsiknya didapati plot cerita yang tidak begitu tersusun, sedikit sebanyak agak mengelirukan pembaca, tetapi ia masih boleh difahami sekiranya fokus penuh diberikan sepanjang proses pembacaan. Perbezaan dimensi masa ketika Fauconnier mula menulis naskhah yang diterbiktan pada tahun 1931 itu dengan gaya penulisan hari ini dan perubahan cara hidup masyarakat mungkin antara perkara yang membataskan untuk pembaca menghayati Nurani Tanah Melayu. Terdapat lukisan atau ilustrasi menarik yang memaparkan gaya hidup masyarakat di Tanah Melayu ketika itu antaranya gaya rumah tradisional, pekerja ladang getah sedang bekerja dan wajah gadis Melayu.

\section{PERBINCANGAN}

Kini kebanyakan karya-karya lama yang berbentuk lisan, baik puisi mahupun prosa telah ditulis dan dibukukan. Dengan demikian orang ramai terutamanya pengkaji sastera Melayu bukan sahaja dapat mengkaji sastera Melayu baharu, mereka juga mendapat kemudahan yang luas mengkaji karya sastera lama. Selain daripad itu kajian mendapati novel ini sarat dengan puisi-puisi Melayu tradisional terutamanya pantun dan mantera. Pantun yang dirakamkan telah menggambarkan betapa geniusnya orang Melayu dalam berbahasa. Ini diakui oleh Fauconnier. Ani Haji Omar (2011:19) menyatakan puisi Melayu tradisional atau puisi rakyat adalah kesusasteraan rakyat yang sudah tertentu dan terikat bentuknya, biasanya terjadi daripada beberapa deret kalimat, ada yang berasaskan mantera, ada yang berdasarkan panjang pendek suku kata, tekanan suara atau hanya berdasarkan pada irama. Puisi rakyat juga terdapat dalam bentuk sastera rakyat non-naratif seperti dalam ungkapan tradisional (peribahasa) yang dinamakan peribahasa berangkap yang wujud dalam teromba (puisi adat), dalam bentuk pertanyaan tradisional atau teka-teki iaitu puisi teka-teki, dalam bentuk cerita rakyat yang dinamakan puisi lirik dan dalam kepercayaan rakyat pula wujud sebagai mantera.

Dalam kesusasteraan Melayu tradisional beberapa jenis puisi telah dikenal pasti yang hidup dalam tradisi lisan sebagai hasil kesusasteraan rakyat. Puisi-puisi tersebut ada yang lahir sebagai hasil kreativiti masyarakat Melayu sendiri dan ada juga yang disadur daripada tradisi luar terutama tradisi Arab-Parsi yang telah dibawa oleh Islam dan ada juga yang disadur daripada tradisi Hindu sebagai serpihan tinggalan budaya tersebut, namun telah diiktiraf sebagai hasil Melayu asli kerana telah berlaku perubahan dan penyesuaian sehingga berbeza daripada bentuk asalnya. Harun Mat Piah (1989) menyatakan terdapat 12 bentuk/jenis puisi Melayu tradisional iaitu pantun, syair, nazam, gurindam, seloka, puisi teka-teki, peribahasa berangkap, teromba, talibun, prosa berirama/prosa lirik, mantera dan dikir/zikir. Kebanyakan puisi-puisi ini wujud dalam bentuk sastera lisan yang disampaikan dari mulut ke mulut sebelum adanya alat percetakan dan kebanyakan rakyat pada ketika itu tidak tahu membaca dan menulis. Namun untuk ulasan dalam kertas kerja ini hanya beberapa contoh daripada puisi tradisional tersebut akan diketengahkan.

Jines Reeves (1980:271) menyatakan sastera lisan berperanan sebagai medium imaginasi kreatif manusia. Oleh yang demikian tidak keterlaluan jika dikatakan bahawa sastera lisan berupa karya kolektif dari genius kolektif yang sebenarnya tidak kurang canggih pandangan hidup atau cara persembahannya. Inilah rupa sastera Melayu sebelum kemunculan medium percetakan. Sehubungan dengan itu Muhammad Haji Salleh (2012) berpendapat bahawa seharusnya kita tidak lupa bahawa kita telah didahului, dimatangkan oleh karya leluhur bangsa kita. Oleh itu kita harus mengkajinya.

Puisi Melayu tradisional banyak mengandungi nasihat yang berguna, petua-petua yang berharga, pantang larang yang harus dielakkan, kiasan yang tepat, sindiran yang tajam, humor yang mengusik hati, undang-undang masyarakat yang perlu dipatuhi. Puisi Melayu tradisional juga dapat 
menyalurkan cita rasa, daya kreatif, bakat, idea serta ilham para seniman dan sasterawan dalam memperkembangkan budaya serta mempertingkat tamadun bangsa. Puisi juga dapat dilihat sebagai suatu sumber penglahiran jiwa yang mencerminkan identiti serta hati budi sesuatu bangsa tersebut. Di samping cintakan tanah air (patriotik) dan dapat memberi kesedaran serta keinsafan seseorang insan terhadap kebesaran dan kekuasaan Tuhan. Selanjutnya dapat dijadikan pedoman hidup yang luhur dan tunjuk ajar yang berfaedah yang kesemuanya mengajar dan mengasuh manusia supaya hidup berbudi bahasa dan berakhlak mulia dan tidak keterlaluan jika dikatakan ia dapat menjana paradigma generasi yang mengamalkannya.

Namun kini puisi Melayu tradisional seakan hilang kegemilangannya. Abdul Latiff Abu Bakar (2006:99) menyatakan bahawa peranan puisi Melayu tradisional kian terpinggir kerana masyarakat tidak lagi melihat kepentingan dan hikmah besar yang terkandung dalam puisi warisan orang tua-tua yang bukan sahaja menggambarkan akal budi orang Melayu yang hebat tetapi tersisip kemas pengajaran adat dengan menggunakan bahasa Melayu yang begitu indah dan komunikatif. Sehubungan dengan itu kertas kerja ini selanjutnya akan menganalisis puisi Melayu tradisional seperti pantun, syair, nazam, gurindam, seloka, dan teromba dan kaitannya dengan akal budi dan pemikiran orang Melayu yang boleh menjana paradigma generasi alaf baharu menerusi maksudnya sama ada secara tersurat mahupun tersirat.

\section{KESIMPULAN}

Secara keseluruhannya Nurani Tanah Melayu ialah simbolik kepada kekuatan Melayu yang selama ini sering dipandang rendah oleh masyarakatnya sendiri, sedangkan ia dihormati oleh orang asing yang mengambil peluang mendalami keunikan budaya dan keseniannya. Membacanya berupaya membuka nurani dan minda masyarakat supaya teguh kepada akarnya, tegar dalam menjaga kedaulatan bangsa dan lebih patriotik seperti saratnya cinta Fauconnier kepada Tanah Melayu. Sesungguhnya bahasa dan kesusasteraan umumnya adalah pancaran citarasa dan corak kehidupan masyarakat. Yang lama adalah pancaran masyarakat dan seni kehidupan lama dan yang baharu merupakan gambaran yang terpancar dalam unsur-unsur seni kehidupan masyarakat baharu. Sebenarnya kedua-duanya itu merupakan budaya bahasa Melayu dan sekaligus memperlihatkan keseluruhan bentuk dan corak kebudayaan Malaysia. Sebagai rumusannya memang benarlah seperti kata Robert Scholes (1969), seorang pengkritik puisi menyatakan bahawa 'orang yang menutup telinga terhadap puisi akan terpencil dari suatu wilayah yang penuh harta kekayaan berupa pengertian manusia, pandangan perseorangan, sensitiviti yang menonjol; oleh itu upaya yang dituntut untuk memahami serta menghayati puisi menjadi sama pentingnya dengan upaya yang dituntut oleh setiap bentuk kehidupan manusiawi lainnya'. Matthew Arnold (1964) pula ketika mengemukakan tanggapannya menyebut, 'puisi adalah satu-satunya cara yang paling indah, impresif dan yang paling efektif untuk mendendangkan sesuatu'.

Dengan tanggapan-tanggapan ini sudah cukup untuk menunjukkan bahawa ketinggian nilai seni puisi terletak pada penciptanya yang mengandungi kekayaan pemikiran serta kehalusan perasaan yang terjalin dalam ukiran bahasa secara harmonis. Maka di sinilah terletaknya keistimewaan kedudukan puisi Melayu sebagai cipta sastera yang unggul.

\section{RUJUKAN}

Ani Hj Omar. (2011). Aspresiasi Teori Kesusasteraan Melayu.Tanjung Malim: Emeritus Publication. Asmad. (1990). Budaya Bahasa (1) Puisi. Kuala Lumpur: Associated Educational Dristributors (M).

Harun Mat Piah, Ismail Hamid \& Siti Hawa Salleh. (1993). Kesusasteraan Melayu Tradisional. Kuala Lumpur: Dewan Bahasa dan Pustaka.

Henri Fauconnier. (2015). Nurani Tanah Melayu (Malaisie). Penterjemah Muhammad Haji Saleh. Kuala Lumpur: Institut Terjemahan dan Buku Malaysia. 
Mohd. Ali Bachik. (1989). Himpunan Puisi Klasik. Shah Alam: Marwilis Publisher and Distributors Sdn. Bhd. Mohd Affandi Hassan. (1994). Kesusasteraan Melayu: Mitos dan Realiti. Kuala Lumpur: Dewan Bahasa dan Pustaka.

Mana Sikana.(1986). Kritikan Sastera, Pendekatan dan Kaedah. Kuala Lumpur: Penerbit Fajar Bakti Sdn. Bhd. Muhammad Haji Salleh. (2008). Permata di Rempat, Gilang Sastera sebagai Ruang Bangsa. Kuala Lumpur: Dewan Bahasa dan Pustaka.

Mohd. Taib Osman. (1984). Warisan Puisi Melayu. Kuala Lumpur: Dewan Bahasa dan Pustaka.

Sahlan Mohd Saman dan Shaiful Bahri Md. Radzi (pnyt.). (2012). Pengantar Pesuratan Melayu, Tradisional ke Moden. Bangi: Penerbit Universiti Kebangsaan Malaysia.

Reeves, J. (1980). Understanding Poetry. London: Pans Book Ltd.

Schools, Robert. (1969). Elements of Poetry: London: Oxford University Press.

Winstedt, R.O. (1969). A.History of Classical Malay Literature. Kuala Lumpur: Oxford University Press.

Za’ba. (1965). Ilmu Mengarang Melayu. Kuala Lumpur: Dewan Bahasa dan Pustaka. 